\title{
Effect of administration of zinc and selenium on lipid peroxidation and endogenous antioxidant enzymes in trypanosoma brucei infected albino rats
}

\begin{abstract}
The effect of administration of zinc and selenium on lipid peroxidation and endogenous antioxidant enzymes in albino rats was investigated. Forty-five (45) healthy rats were divided into nine (9) groups of five (5) rats each. Groups I, II, and III served as control; administered with normal chow and distilled water ad libitum, zinc gluconate and selenium and Trypanosoma brucei without treatment respectively. Groups IV, V, and VI were the pretreated infected groups that were administered with daily dose of 50mg per kilogram body weight of zinc, $10 \mathrm{mg}$ per kilogram body weight of selenium and combination of zinc and selenium respectively for seven (7) days. Whereas group VII, VIII and IX represented the post-infected treated groups that were administered with daily dose of 50mg per kilogram body weight of zinc, $10 \mathrm{mg}$ per kilogram body weight of selenium and combination of zinc and selenium respectively for seven (7) days. The control group of Trypanosoma brucei infected without treatment showed a significant $(\mathrm{P}<0.05)$ increase in the concentration of malondialdehyde (MDA), and decrease in superoxide dismutase (SOD), catalase (CAT) and glutathione peroxidase (GPx) activities when compared with other control groups. Administration of zinc and selenium to the pre and post-infected groups caused significantly $(\mathrm{P}<0.05)$ lower values in the concentration of malondialdehyde (MDA), with significantly $(\mathrm{P}<0.05)$ higher activities of superoxide dismutase (SOD), catalase (CAT) and glutathione peroxidase (GPx) in the liver and kidney. Treatment with zinc and selenium may contribute in protection against cellular damage during Trypanosoma brucei infection in rats.
\end{abstract}

Keywords: zinc, selenium, malondialdehyde, superoxide dismutase, catalase, glutathione peroxidase, trypanosoma brucei
Volume 2 Issue $6-2018$

\author{
Victor Duniya Sheneni,Victor Akagwu Odiba, \\ Favour Moses Idih \\ Department of Biochemistry, Kogi State University, Ayingba, \\ Nigeria
}

Correspondence: Sheneni Victor Duniya, Department of Biochemistry, Faculty of Natural Sciences, Kogi State University, PMB 1008, Anyigba, Nigeria, Tel +234-8033519009,

Email sheninivictor@gmail.com

Received: October 24, 2018 | Published: November 01, 2018
Abbreviations: MDA, malondialdehyde; SOD, superoxide dismutase; CAT, catalase; CuZnSOD, copper-zinc superoxide dismutase; GPx, glutathione peroxidase; ROS, reactive oxygen species; TrxR, thioredoxin reductase; RNS, reactive nitrogen species; IDD, iodothyronine deiodinases

\section{Introduction}

Zinc $(\mathrm{Zn})$ is a micronutrient and a very abundant trace element in the body with diverse roles in biological, clinical and global public health. ${ }^{1-3}$ It is an important trace element for all forms of life, and acts as important component of biological antioxidant systems. ${ }^{4}$ A lot of enzymes use zinc in one form or the order to achieve their biological function, and as such, are involved in numerous aspect of cellular metabolism. Due to its interaction with numerous enzymes as a co-factor, they are necessary for growth, optimum performance and modulation of immune system. ${ }^{5}$ In addition, Zinc is important as they perform roles in the structure and function of biological membranes, ${ }^{6}$ it has been shown to have an antioxidant potential and also exert critical physiological role in regulating the structure and function of cells. ${ }^{7,8}$ Zinc is specifically needed for the complete formation and function of the antioxidant enzyme; copper-zinc superoxide dismutase (CuZnSOD) and various metallothioneins. ${ }^{9}$ It performs a vital role in the antioxidative defense of cells. ${ }^{10}$ Selenium (Se) is an important component of antioxidant enzymes such as glutathione peroxidase (GPx), thioredoxin reductase (TrxR) and iodothyronine deiodinases (IDD). It is also a natural antioxidant ${ }^{11}$ and immunostimulant. ${ }^{12-14}$ Recently, research on selenium has increased greatly due to its vital function in antioxidant seleno-proteins for protection against oxidative stress initiated by excess reactive oxygen species (ROS) and reactive nitrogen species (RNS) ${ }^{15}$ Its activity helps to maintain membrane integrity, protects prostacyclin production and decreases the likelihood of propagation of further oxidative damage to biomolecules such as lipids, lipoproteins and DNA with the associated increased risk of didtysease conditions such as atherosclerosis and cancer. ${ }^{16}$

Trypanosoma brucei belongs to the order Kinetoplastida and is considered part of the earliest diverging eukaryotic lineages. ${ }^{17}$ Therefore; they are regarded as a "model organism" for studying other alternative mechanisms by which eukaryotes are able to perform basic functions. During their life cycle, trypanosomes encounter the vastly different environments of the mammalian bloodstream and various tissues within the tsetse vector. They respond to these by dramatic morphological and metabolic changes, including adaptation of their lipid and energy metabolism. ${ }^{18}$ There are three sub-species of the Trypanosoma brucei, namely; Trypanosoma brucei, Trypanosoma brucei rhodesiense and Trypanosoma brucei gambiense. ${ }^{19}$ Trypanosoma brucei belongs to the sub-genus Trypanozoon, which is responsible for causing Nagana in cattle. Horses, dogs, cats, camels and pigs are very susceptible to Trypanosoma brucei infection. Infection of cattle, sheep, goats and sometimes pigs results in mild or chronic infection. ${ }^{20}$ Moulton \& Sollod, ${ }^{21}$ showed evidence of this organisms wide-spread in East and West sub-Saharan Africa causing serious disease and high death rate in cattle, sheep, and goats. Trypanosomiasis is one of the oldest and neglected tropical diseases (WHO, 2008) causing much trouble to man, mainly in sub-Saharan Africa and parts of South America. Tsetse fly, belonging to the genus 
Glossina is responsible for transmitting the disease (Trypanosomiasis), endemic in 36 sub-Saharan African countries posing a serious setback to improved and profitable livestock production and mixed croplivestock farming development in the African continent. ${ }^{22-24}$ The disease is called sleeping sickness in humans, Nagana in cattle and Surra in Camels. ${ }^{25}$

\section{Materials and methods}

\section{Materials}

\section{Chemicals/reagents}

All chemicals used were of analytical grade. Hydrogen Peroxide, Sodium chloride, Sodium hydroxide, Sodium carbonate, Sodium bicarbonate, Acetic acid, Potassium dichromate, Potassium phosphate, Potassium iodide, Picric acid, Hydrochloric acid, Dinitrophenyl hydrazine, Magnesium chloride, Copper sulphate, Sodium citrate, Dipotassium phosphate, Trichoroacetic acid, Adrenalin, Thiobarbituric



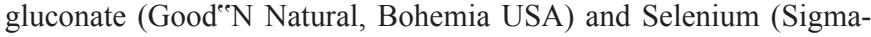
Aldrich $\left.{ }^{\circledR}\right)$.

\section{Experimental animals}

A total of fifty four (54) healthy albino rats of both sexes, weighing between $200-250 \mathrm{~g}$, were used for the experiment. The rats were purchased from the Department of Pharmacology animal house, Ahmadu Bello University Zaria, Nigeria. The animals were kept in well-aerated laboratory cages and allowed to adjust to the laboratory environment for a period of two weeks before commencement of the experiment. They were fed with standard feed (Vital Feeds, Jos, Nigeria) and water was provided ad libitum.

\section{Trypanosome isolates}

Strain of Trypanosoma brucei was obtained from the stabilates that was cryopreserved in a Vector in Parasitology Studies Department, Nigerian Institute for Trypanosomiasis Research (NITR), Kaduna, Nigeria.

\section{Methods}

\section{Induction of parasitaemia}

The parasite was maintained by serial passage in a donor rat. The infected blood from the donor rat was collected and diluted with phosphate buffered saline (PBS). The number of parasites in the diluted blood was determined (Herbert and Lumsden, 1976) and $0.1 \mathrm{~mL}$ of blood containing approximately $1 \times 103$ trypanosomes was inoculated intraperitoneally into each rat in the infected groups.

\section{Experimental design}

A total of forty-five (45) rats were used. The rats were randomized into nine (9) groups consisting of five (5) rats per group. Groups I, II and III served as control while group IV, V and VI served as pretreated infected rats that were administered with daily dose of $50 \mathrm{mg}$ per kilogram body weight of zinc gluconate, ${ }^{26} 10 \mathrm{mg}$ per kilogram body weight of selenium ${ }^{15}$ and combination of zinc gluconate and selenium respectively for seven (7) days. Groups VII, VIII and IX served as post-infected treated groups that were administered with daily dose of $50 \mathrm{mg}$ per kilogram body weight of zinc gluconate, ${ }^{26}$ $10 \mathrm{mg}$ per kilogram body weight of selenium ${ }^{15}$ and combination of zinc gluconate and selenium immediately after parasite was sighted in the blood for seven (7) days. ${ }^{27}$

\section{Grouping and treatment}

\section{Control groups:}

Group I (NC): Normal rats fed with normal chow and distilled water ad libitum

Group II $(\mathrm{N}+\mathrm{Zn}+\mathrm{Se})$ : Normal rats treated with zinc gluconate + selenium

Group III (TC): Trypanosoma brucei brucei infected untreated rats

\section{Pre-infected treated groups:}

Group IV $($ Pre $+\mathrm{Zn})$ : Trypanosoma brucei brucei infected rats + zinc gluconate

Group V (Pre + Se): Trypanosoma brucei brucei infected rats + selenium

Group VI (Pre $+\mathrm{Zn}+\mathrm{Se})$ : Trypanosoma brucei brucei infected rats + zinc gluconate + selenium

\section{Post-infected treated groups:}

Group VII (Post + Zn): Trypanosoma brucei bruceiinfected rats + zinc gluconate

Group VIII (Post + Se): Trypanosoma brucei bruceiinfected rats + selenium

Group IX (Post $+\mathrm{Zn}+\mathrm{Se})$ : Trypanosoma brucei bruceiinfected rats + zinc gluconate + selenium

\section{Collection and preparation of samples for analysis}

At the end of the experiment, the liver and kidney were excised, trimmed of connective tissues, rinsed with saline to eliminate any form of blood contamination, dried by blotting with filter paper, and kept in the freezer. The liver and kidney were crushed; $50 \mathrm{mM}$ potassium phosphate buffer ( $\mathrm{pH}$ 7.4) was used for homogenization. A certain weight of the organ was taken and buffer was added to a certain total volume, and then homogenised. It was centrifuged at 4000rpm for $15 \mathrm{~min}$. Then, the supernatant was collected using Pasteur pipette. Lipid peroxidation of low density lipoprotein (LDL) as evidenced by the level of malondialdehyde (MDA) concentration was assessed by Thiobarbituric acid reactive substances (TBARS) formation described by Ohkawa et al., ${ }^{28}$ Superoxide dismutase (SOD) activity was determined by method of Fridovich (1989), Catalase (CAT) activity was determined using the method described by Sinha (1972) and Glutathione peroxidase (GPx) activity by method described by Ellman. ${ }^{29}$

\section{Data analysis}

Results were expressed as mean \pm standard deviation (SD). The data obtained were analyzed using analysis of variance (ANOVA) (SPSS program, version 20 SPSS Inc., Chicago, IL, USA for windows Computer software Package). The difference between the experimental groups were compared using the Duncan Multiple Range Test. Values of $\mathrm{P}$ less than $0.05(\mathrm{P}<0.05)$ were taken as significant.

\section{Results}

\section{Effect on liver lipid peroxidation}

Table 1 shows lipid peroxidation level of malondialdehyde (MDA) in the liver of normal and trypanosomiasis infected rats administered with zinc and selenium for seven (7) days. Rats that were infected with 
Trypanosoma brucei brucei untreated shows significantly $(\mathrm{P}<0.05)$ higher concentration of MDA compared to other control groups. Animals that were treated; pre and post infection showed a significantly $(\mathrm{P}<0.05)$ higher concentration of MDA when compared to the normal feed and water and combined $\mathrm{Zn}+\mathrm{Se}$ control groups. However, there was an exception in the pre-infected treated and post-infected treated groups administered with $\mathrm{Zn}+\mathrm{Se}$. The MDA concentration of all the pre and post infected treated showed a significantly $(\mathrm{P}<0.05)$ lower value when compared to the infected untreated Trypanosoma brucei brucei control group.

Table I Effect of Administration of Zinc and Selenium on Lipid Peroxidation and Endogenous Antioxidant Enzymes in Trypanosoma brucei brucei Infected Wistar Albino Rats in the Liver

\begin{tabular}{|c|c|c|c|c|}
\hline Group & MDA(mmol/g of tissue) & SOD(mmol/min/g of tissue) & CAT(moles of $\mathrm{H}_{2} \mathrm{O}_{2} / \mathrm{min} / \mathrm{g}$ of tissue) & GPx(mU/mL) \\
\hline NC & $2.35 \pm 0.33^{\mathrm{a}}$ & $3.18 \pm 0.19^{e}$ & $52.00 \pm 1.26^{\mathrm{b}}$ & $51.00 \pm 2.23 b^{c}$ \\
\hline $\mathrm{N}+\mathrm{Zn}+\mathrm{Se}$ & $2.36 \pm 0.18^{a}$ & $3.13 \pm 0.16^{e}$ & $53.17 \pm 2.14^{b}$ & $49.83 \pm 1.94 b^{c}$ \\
\hline TC & $2.95 \pm 0.26^{c}$ & $2.28 \pm 0.46^{\mathrm{a}}$ & $43.33 \pm 1.63^{\mathrm{a}}$ & $42.00 \pm 4.38^{\mathrm{a}}$ \\
\hline $\mathrm{PRE}+\mathrm{Zn}$ & $2.65 \pm 0.28^{b}$ & $2.92 \pm 0.15^{d}$ & $53.00 \pm 1.03 b^{c}$ & $49.33 \pm 1.86 b^{c}$ \\
\hline $\mathrm{PRE}+\mathrm{Se}$ & $2.67 \pm 0.29^{b}$ & $2.87 \pm 0.20^{\mathrm{bc}}$ & $53.00 \pm 1.74 b^{c}$ & $48.59 \pm 2.59 b^{c}$ \\
\hline $\mathrm{PRE}+\mathrm{Zn}+\mathrm{Se}$ & $2.43 \pm 0.38^{\mathrm{a}}$ & $3.00 \pm 0.05^{c d}$ & $55.67 \pm 2.80^{c}$ & $51.50 \pm 1.23^{c}$ \\
\hline POST + Zn & $2.70 \pm 0.33^{b}$ & $2.77 \pm 0.18^{c}$ & $53.83 \pm 3.06 b^{c}$ & $49.67 \pm 2.73 b^{c}$ \\
\hline $\mathrm{POST}+\mathrm{Se}$ & $2.77 \pm 0.23^{b}$ & $2.53 \pm 0.3 \mathrm{I}^{\mathrm{b}}$ & $53.50 \pm 3.08 b^{c}$ & $47.17 \pm 3.06^{b}$ \\
\hline $\mathrm{POST}+\mathrm{Zn}+\mathrm{Se}$ & $2.44 \pm 0.32^{\mathrm{a}}$ & $2.90 \pm 0.2 \mathrm{lb}^{\mathrm{cd}}$ & $52.17 \pm 2.79 b^{c}$ & $49.00 \pm 1.53 b^{c}$ \\
\hline
\end{tabular}

Values are means \pm SD of five replicate determinations. Values with different superscript down the column are significantly different $(P<0.05)$.

Table 2 Effect of Administration of Zinc and Selenium on Lipid Peroxidation and Endogenous Antioxidant Enzymes in Trypanosoma brucei brucei Infected Wistar Albino Rats in the Kidney

\begin{tabular}{|c|c|c|c|c|}
\hline Group & MDA(mmol/gof tissue) & SOD(mmol/min/gof tissue) & CAT(moles of $\mathrm{H}_{2} \mathrm{O}_{2} / \mathrm{min} / \mathrm{g}$ of tissue) & $\operatorname{GPx}(\mathrm{mU} / \mathrm{mL})$ \\
\hline NC & $2.40 \pm 0.13^{a}$ & $3.37 \pm 0.30^{d}$ & $48.50 \pm 1.33^{b}$ & $46.17 \pm 1.17^{b}$ \\
\hline $\mathrm{N}+\mathrm{Zn}+\mathrm{Se}$ & $2.30 \pm 0.14^{\mathrm{a}}$ & $3.22 \pm 0.21^{d}$ & $49.00 \pm 1.22^{b}$ & $46.67 \pm 2.80^{b}$ \\
\hline $\mathrm{TC}$ & $2.78 \pm 0.23^{d}$ & $2.63 \pm 0.27^{a}$ & $34.67 \pm 3.93^{\mathrm{a}}$ & $39.50 \pm 1.38^{\mathrm{a}}$ \\
\hline $\mathrm{PRE}+\mathrm{Zn}$ & $2.58 \pm 0.17^{\mathrm{bc}}$ & $3.25 \pm 0.24^{b}$ & $47.83 \pm 1.14^{b}$ & $47.17 \pm 1.94^{b}$ \\
\hline $\mathrm{PRE}+\mathrm{Se}$ & $2.63 \pm 0.25^{b c}$ & $2.95 \pm 0.24^{\mathrm{ab}}$ & $47.17 \pm 3.06^{b}$ & $49.83 \pm 1.60^{c}$ \\
\hline $\mathrm{PRE}+\mathrm{Zn}+\mathrm{Se}$ & $2.45 \pm 0.22^{b}$ & $3.98 \pm 0.27^{b}$ & $48.60 \pm 0.22^{b}$ & $47.00 \pm 2.37^{b}$ \\
\hline $\mathrm{POST}+\mathrm{Zn}$ & $2.68 \pm 0.19^{b c}$ & $2.80 \pm 0.28^{\mathrm{ab}}$ & $46.00 \pm 3.22^{b}$ & $46.15 \pm 3.11^{b}$ \\
\hline $\mathrm{POST}+\mathrm{Se}$ & $2.70 \pm 0.23^{c}$ & $2.75 \pm 0.19^{\mathrm{ab}}$ & $45.25 \pm 1.82^{b}$ & $47.12 \pm 2.8 I^{b}$ \\
\hline $\mathrm{POST}+\mathrm{Zn}+\mathrm{Se}$ & $2.46 \pm 0.24^{b}$ & $3.91 \pm 0.32^{c}$ & $47.08 \pm 2.00^{\mathrm{b}}$ & $46.08 \pm 3.28^{b}$ \\
\hline
\end{tabular}

Values are means \pm SD of five replicate determinations. Values with different superscript down the column are significantly different $(P<0.05)$.

\section{Effect on liver antioxidants}

The result shows that normal rats that were administered combined $\mathrm{Zn}+\mathrm{Se}$ without infection had no significant $(\mathrm{P}>0.05)$ difference in liver antioxidant enzymes (SOD, CAT, and GPx) activities compared to the normal feed and water control group animals (Table 1). There was a significantly $(\mathrm{P}<0.05)$ lower activities of liver antioxidant enzymes (SOD, CAT, and GPx) in infected untreated group when compared to the normal feed and water and combined $\mathrm{Zn}+\mathrm{Se}$ control groups. The pre and post infected treated rats showed a significantly $(\mathrm{P}<0.05)$ lower activity in SOD when compared with the normal feed and water control group animals. All the pre and post Trypanosoma brucei infected treated rat showed a significantly $(\mathrm{P}<0.05)$ higher activities of liver antioxidant enzymes (SOD, CAT, and GPx) when compared to the infected untreated Trypanosoma brucei group.

\section{Effect on the kidney lipid peroxidation}

Trypanosoma brucei infected untreated rats showed a significantly $(\mathrm{P}<0.05)$ higher concentration of MDA when compared to the normal feed and water and combined $\mathrm{Zn}+\mathrm{Se}$ control groups (Table 2). Rats in the pre and post infected treated groups showed a significantly $(\mathrm{P}<0.05)$ high concentration of MDA when compared to the normal feed and water and combined $\mathrm{Zn}+\mathrm{Se}$ control groups. The pre and post infected treated groups showed a significantly $(\mathrm{P}<0.05)$ lower concentration of MDA compared to the infected untreated Trypanosoma brucei control group.

\section{Effect on the kidney antioxidants}

The result shows that there was a significantly $(\mathrm{P}<0.05)$ lower activities of kidney antioxidant enzymes (SOD, CAT and GPx) in the infected untreated group when compared to the normal feed and water and combined $\mathrm{Zn}+\mathrm{Se}$ control groups (Table 2). The treated pre and post infected groups showed a significant $(\mathrm{P}<0.05)$ increase in SOD, CAT and GPx activities when compared to Trypanosoma brucei infected untreated control group.

\section{Discussion}

Trypanosomiasis was inflicted on the rats when they were injected with trypanosomes and therefore, provides animal models of 
experimentally infected trypanosomiasis. The parasite Trypanosoma brucei produces a very severe acute stress in the infected rats. Oxidative stress describes a higher pro-oxidant load compared to the antioxidant defense system in the body, leading to a potential damage..$^{30}$ During oxidative stress, there is a general reduction of the free radical defense mechanism in the body, which includes changes in the activities of antioxidant enzymes, essential polyunsaturated fatty acids, compromise of vitamins and minerals elements, thereby exposing the body's own antioxidant defense system and making them vulnerable to damage by reactive oxygen species (ROS) (Omoregie and Osagie, 2011). Malondialdehyde (MDA) is the major oxidation product of the peroxidation of polyunsaturated fatty acids, and MDA formed is measured quantitatively by the reaction with thiobarbituric acid reactive substances (TBARS), thereby an elevated MDA concentration, reflects as an important index to lipid peroxidation. Free radical scavengers and chain terminator enzymes such as superoxide dismutase (SOD), catalase (CAT) and glutathione peroxidase (GPx) system protect the biological system against the damaging effects of oxidants and activated species. ${ }^{31}$ Catalase is an enzymatic antioxidant that can be found virtually in all animal tissues including the red blood cell and liver. It degrades hydrogen peroxide $\left(\mathrm{H}_{2} \mathrm{O}_{2}\right)$ and helps protect the tissues from highly reactive hydroxyl radicals. SOD, another antioxidant enzyme, removes superoxide radical by converting it to $\mathrm{H}_{2} \mathrm{O}_{2} \cdot{ }^{32}$

Glutathione protects the cellular system against the harmful negative effects of lipid peroxidation. In this present study, the results shown in Table $1 \&$ Table 2 shows that concentrations of MDA were significantly $(\mathrm{P}<0.05)$ higher in liver and kidney tissue homogenates of infected untreated rats compared to the pre and post-infected treated and normal feed and water control groups. The depression in the concentration of MDA in liver and kidney tissue homogenates following administration of zinc and selenium confirm their antioxidant properties. ${ }^{9}$ The micronutrients may have also prevented or delayed the on-set of oxidative stress which arises as a result of imbalance between radical-generating and radical-scavenging activity. Ogunsanmi et al., ${ }^{33}$ have shown in earlier study that oxidative stress plays an important etiologic role in the pathogenesis of trypanosomiasis. In the same vein, it has also been demonstrated that infections with Trypanosoma brucei group of parasites may change the host's antioxidant defense against free radicals. ${ }^{34,35}$ Elevated MDA concentrations have been related to the amount of stress and are well correlated with lipid membrane damage and loss of membrane integrity. Increased production of MDA in plasma, tissues and erythrocytes was also reported in murine models and humans infected with Trypanosoma cruzi. ${ }^{36}$ Aleksandro et al. ${ }^{27}$ reported that plasma MDA concentrations were significantly higher in animals infected by Trypanosoma evansi than in the uninfected group, and in animals with acute (day 21) and chronic (day 49) trypanosomiasis, MDA levels were also found to be proportional to the time of infection.

Intraperitonial administration of zinc and selenium in the pre and post-infected rats resulted in increased activities of GPx in liver and kidney (Table 1) (Table 2) when compared with the infected untreated rats. The depressed activity of GPx observed in the liver and kidney of infected untreated rats is an indication of an increased utilization due to oxidative stress. This is probably due to their antioxidant defense system which includes GPx was mobilized to fight the presence of the parasites. This is congruent with previous studies that showed a decrease in erythrocytic and hepatic glutathione concentrations in rats infected with Trypanosoma brucei ${ }^{37}$ The trypanosome infection causes the oxidation of GSH to GSSH by activated oxygen and is partly responsible for the significantly lower concentration of glutathione peroxidase in the liver and kidney tissue homogenate of infected untreated rats compared to the pre and post-infected treated groups, ${ }^{33,34}$ also, the high increase in the activity of glutathione peroxidase can also be attributed to its lower concentration ${ }^{35}$ since the reaction catalyzed by this enzyme consumes GSH. Likewise, reports have shown that depletion of endogenous glutathione antioxidant may be a significant factor in the pathogenesis of Trypanosoma Scongolense infection but upon administration of exogenous vitamin $\mathrm{C}$ to infected animals prevented these disease-induced decreases in glutathione and ascorbic acid. ${ }^{38}$

Catalase (CAT) is a peroxisomal maker enzyme found in blood, bone marrow, mucous membrane, kidney and liver. It functions assumed to be destruction of hydrogen peroxide. The result of this study showed an increase in liver and kidney CAT activities in the pre and post infection treated groups when compared with the infected untreated group (Table 1) (Table 2). Oluwatosin et al., ${ }^{39}$ observed that the decrease in the activity of catalase could be attributed to its use in mopping up the free radicals overload which is produced during trypanosome infection. Superoxide dismutase (SOD) is also an endogenous antioxidant enzyme that protects blood cells from oxidative stress and damage. The result of this study showed lower SOD activities in liver and kidney in the infected untreated control compared to the pre and post-infected treated groups. This could be as a result of increased removal of superoxide anions. Omer et al., ${ }^{35}$ reported decreased SOD activity in Trypanosoma evansi infected rats. However, others reported increased SOD activity. ${ }^{40-47}$ Conditions of oxidative stress increases the activities of antioxidant enzymes such as SOD, CAT and glutathione peroxidise as reported by Ataley et al. ${ }^{41}$

\section{Conclusion}

This study shows that administration of zinc and selenium prevented depletion of endogenous antioxidant enzymes (superoxide dismutase, catalase and glutathione peroxidase) in the liver and kidney. Therefore, understanding the role of these micronutrients in the pathogenesis of diseases associated with oxidative stress may help in designing nutritional support and control programs as a strategy to combating the effect of the diseases.

\section{Acknowledgements}

None.

\section{Conflict of interest}

The author declares there is no conflict of interest.

\section{References}

1. Dalla Rosa L, Aleksandro SD, Camila BO, et al. Trypanosoma evansi: Effects of Zinc and Copper in experimentally infected Rats. Experimental Parasitology. 2012;131:358-362.

2. Hambidge KM, Miller VV, Westcott JE, et al. Zinc bioavailability and homeostasis. Journal of Clinical Nutrition. 2010;91(5):1478s-1483s.

3. Zhou Z, Kang X, Jiang Y, et al. Preservation of hepatocyte nuclear factor4 á is associated with zinc protection against TNF-á hepatotoxicity in mice. Experimental Biology and Medicine. 2007;232(5):622-628.

4. Sahin K, Kucuk O. Zinc supplementation alleviates heat stress in laying Japanese quail. Journal of Nutrition. 2003;133(9):2808-2811.

5. Zago M, Oteiza PI. The antioxidant properties of zinc interactions with iron and antioxidants. Free Radical Biology and Medicine. 2001;31(2):266274.

6. Bettger WJ, BL O'Dell. Physiological roles of zinc in plasma membrane of mammalian cells. Journal of Nutrition and Biochemistry. 1993;4:194-207. 
7. Powell SR. The antioxidant properties of zinc. Journal of Nutrition. 2000;130(Suppl 5):1447-1454.

8. Sidhu P, Garg ML, Dhawan DK. Protective effects of zinc on oxidative stress enzymes in liver of protein deficient rats. NutriciónHospitalaria. 2004;19(6):341-347.

9. DiSilvestro RA. Zinc in relation to diabetes and oxidative disease. Journal of Nutrition. 2000;130:1509s-1511s

10. Bonnefont-Rousselot D. The role of antioxidant micronutrientents in the prevention of diabetic complications. Treat Endocrinology. 2004;3(1):4152.

11. Tapiero H, Townsend DM, Tew KD. The antioxidant role of selenium and seleno-compounds. Biomedical Pharmacy. 2003;57(3-4):134-44.

12. Beck MA, Levander OA, Handy J. Selenium deficiency and viral infection. Journal of Nutrition. 2003;133(Supple 1):1463S-1467S.

13. Broome CS, Mcardle F, Kyle JAM, et al. An increase in selenium intake improves immune function and poliovirus handling in adults with marginal selenium status. American Journal of Clinical Nutrition. 2004;80(1):154 162.

14. Kiremidjian-Schumacher L, Roy M, Wishe HI, et al. Supplementation with selenium and human immune cell functions. II. Effect on cytotoxic lymphocytes and natural killer cells Biology. Trace Element Research. 1994;41(1-2):115-127.

15. Rayman MP. Selenium and human health. $A$ Review. Lancet 2012;379(9822):1256-1268

16. Néve J. Selenium as a risk factor for cardiovascular diseases. Journal of Cardiovascular Risk. 1996;3(1):42-47.

17. Simpson AG, Stevens JR, Lukes J. The evolution and diversity of kinetoplastid flagellates. Trends in Parasitology. 2006;22(4):168-174.

18. Hannaert V, Bringaud F, Opperdoes FR, et al. Evolution of energy metabolism and its compartmentation in Kinetoplastida. Kinetoplastid Biology Disorder. 2003;2(1):11.

19. Hoare CA. The Trypanosomes of mammals: a zoological monograph Blackwell Scientific Publications, Oxford UK, 1972. 749 p.

20. Mulligan HW. The African trypanosomiasis. George Allen and Unwin Ltd, UK. 1970. p 950.

21. Moulton JE, Sollod AE. Clinical, serological and pathological changes in calves with experimentally induced Trypanosoma brucei infection. American Journal of Veterinary Research. 1976;37(7):791-802.

22. Adamu S, Ige AA, Jatau ID, et al. Changes in the serum profiles of lipids and cholesterol in sheep experimental model of acute African trypanosomosis. African Journal of Biotechnology. 2008;7(12):2090-2098.

23. Stevens JR, Brisse S. Systematics of trypanosomes of medical and veterinary importance. In: Maudlin I, Holmes $\mathrm{PH}$, editors. The trypanosomiasis. CABI Publishing, Wallingford, 2004:1-23.

24. Swallow BM. Impacts of Trypanosomiasis on African agriculture. PAAT Technical and Scientific Series 2. Food and Agriculture Organisation (FAO), Rome. 2002. 52 p.

25. Welburn SC, Coleman PG, Maudlin I, et al. Crisis, what crisis? Control of Rhodesian sleeping sickness. Trends in Parasitology. 2006;22(3):123-128.

26. Ambali SF, Abubakar Kawu MU, Uchendu C. Biochemical alterations induced by subchronic chlorpyrifos exposure in Wistar rats: ameliorative effect on zinc. The Journal of American Science. 2011;7(9):73-81.

27. Aleksandro SD, Marcio MC, Patricia W, et al. Trypanosoma evansi: Haematological changes in experimentally infected cats. Experimental Parasitology. 2009;123(1):31-34

28. Ohkawa H, Ohishi N, Yagi K. Assay for lipid peroxides in animal tissues by thiobarbituric acid reaction. Annals of Biochemistry. 1979;95(2):351358
29. Ellman GC. Tissue sulfhydryl groups. Archive of Biochemistry and Biophysics. 1959;82(1):70-77.

30. Sies H, Stahl W, Sevanian A. Nutritional, dietary and postprandial oxidative stress. Journal of Nutrition. 2005;135(5):969-972.

31. Kurata M, Suzuki M, Agar NS. Antioxidant systems and erythrocyte life-span in mammals. Comparative Biochemistry and Physiology. 1993;106(3):477-487

32. Krishnaraju AV, Rao CV, Rao TVN, at 1 . In vitro and in vivo antioxidan activity of Aphanamixispolystachya bark. American Journal of Infectious Diseases. 2009;5(2):60-67.

33. Ogunsanmi AO, Taiwo VO. Pathobiochemical mechanism involved in the control of the disease caused by Trypanosoma congolensein African grey duiker (Sylvicapragrimmia). Veterinary Parasitology. 2001;96(1):51-63.

34. Igbokwe IO, Umar IA, Omage JJ, et al. Effect of acute Trypanosoma vivax infection on cattle erythrocyte glutathione and susceptibility to in vitro peroxidation. Veterinary Parasitology. 1996;63(3-4):215-224.

35. Omer OH, Mousa HM, Al-Wabel N. Study on the antioxidant status of rats experimentally infected with Trypanosoma evansi. Veterinary Parasitology. 2007;145(1-2):142-145.

36. Malvezi AD, Cecchini $\mathrm{R}$, De Souza $\mathrm{F}$, et al. Involvement of nitric oxide (NO) and TNFalpha in the oxidative stress associated with anemia in experimental Trypanosoma cruziinfection. FEMS Immunology Medical Microbiology. 2004;41(1):69-77.

37. Ameh DA. Depletion of reduced glutathione and the susceptibility of erythrocytes to oxidative hemolysis in rats infected with $T$. brucei gambiense. IRCS. Journal of Medical Science. 1984;12(2):130.

38. Umar IA, Ibrahim MA, Fari NA, et al. In-vitro and in-vivo antiTrypanosoma evansiactivities of extracts from different parts of Khaya senegalensis. Journal of Cell and Animal Biology. 2010;4(6):91-95.

39. Oluwatosin KS, Habibat U, Usman YU. Effect of methanolic leaf extract of Thymus vulgaris on some biomarker enzymes in Trypanosoma bruce infected rats. International Journal of Pharmaceutical and Biomedical Research. 2013;4(2):83-87.

40. Yusuf AB, Umar IA, Nok AJ. Effects of methanol extract of Vernonia amygdalinaleaf on survival and some biochemical parameters in acute Trypanosoma brucei bruceiinfection. African Journal of Biochemistry Research. 2012;6(12):150-158.

41. Ataley M, Laksonem DE, Khanna S, et al. Vitamin E regulates changes in tissues antioxidant induces by fish oil and exercise. Medical Science Sport Exercise. 2000;32(3):601-607.

42. Debjit B, Chiranjib KP, Sampath K. A potential medicinal importance of zinc in human health and chronic disease. A Review. International Journal of Pharmacy Biomedical Science. 2010;1(1):5-11.

43. Fridovich I. Oxygen radicals from acetaldehyde. Free Radical in Biology and Medicine. 1989;7:557-558.

44. Herbert WJ, Lumsden WHR. Trypanosoma brucei: A rapid "matching" method for estimating the host"sparasitemia. Experimental Parasitology. 1976;40(3):427-431.

45. Omoregie ES, Osagie AU. Effect of Jatropha tanjorensisleaves supplement on the activities of some antioxidant enzymes, vitamins and lipid peroxidation in rats. Journal of Food Biochemistry. 2011;35(2):409-

46. Sinha KA. Calorimetric assay of catalase. Analytical Biochemistry. 1972;47(2):389-394

47. World Health Organization. Control of Neglected Tropical Diseases (NTD). 2008. 